\title{
Fine Structure of Pituitary Acidophils in Thyroidectomized Rats with or without the Treatment with Thyroxine and Dexamethasone
}

\author{
KANJI HARUMIYA \\ Department of Anatomy, Jikei University School of Medicine, \\ Minato-ku, Tokyo
}

\begin{abstract}
Synopsis
Electron microscopic study was made on rat anterior pituitaries in an attempt to clarify the causal mechanism of "loss of acidophils" which could be detected with the light microscope following thyroidectomy. In the advancing days after thyroidectomy, the acidophils (somatotrophs) were gradually deprived of their large granules whose diameter was about $350 \mathrm{~m} \mu$. There was evidence in vivo for the first time that there were some acidophils containing only the small granules, about $130 \mathrm{~m} \mu$ in diameter, after the 7 th postoperative day. This clearly showed the simultaneous existence of two different sizes of granules in the same acidophils. As time elapsed, the large granules dispersed from the acidophils. After the 30th day these acidophils began to adjust their shape into the polygonal cells. Eventually, the acidophils completely lacking granules of either size occassionally appeared on the 90th and 200th days. Thus thyroidectomy had a strong influence to release the large granules, whereas an influence to release the small ones was not remarkable. The replacement injection of thyroxine into the thyroidectomized rats efficaciously reproduced the large granules which were generally considered to be responsible for GH storage. The repeated administrations of dexamethasone to the thyroidectomized rats resulted in the increase in number of small granules that were thought by us to be the storage carriers of ACTH. On the other hand, this compound alleviated loss of large granules following thyroidectomy. The final fate of acidophils after thyro:cectomy was, however, still vague because of the equivocal distinguishment of these degranulated acidophils from the immature basophils. Thus, the "loss of acidophils" may not mean the intrinsic disappearance of the cells themselves, but represent a transient loss of the large dense granules in the remaining acidophils.
\end{abstract}

A remarkable loss of the pituitary acidophils following thyroidectomy was observed on the level of light microscopy (Purves and Griesbach, 1946; Koneff et al., 1949; Knigge, 1955, 1958; Meyer and Evans 1964). It was also reported that after thyroidectomy the pituitary GH content was lowered while the serum GH activity was elevated (Contopoulos et al., 1958; Solomon and Greep, 1959; Amerbury et al., 1965; Schooley et al., 1966). Ishikawa et al. (1972) centrifuged pellets of the isolated acidophils less contaminated with

Received for publication August 25, 1972. the cells of other kind and classified acidophil granules into two patterns according to their diameter; the large ones approximately 350 $\mathrm{m} \mu$ and the small ones, about $130 \mathrm{~m} \mu$. These authors verified by bioassay that the small granules were of ACTH activity while the large ones were of GH activity. Since no investigators have attempted particularly to make the electron microscopical interpretation for "loss of acidophils". following thyroidectomy, the intrinsic mode of "loss of acidophils" has not been concluded yet (Herlant, 1964). This investigation deals with an information that thyroidectomy had a strong influence to 
release the large granules regarded as the storage carriers of $\mathrm{GH}$ from the acidophils and produced a slight influence to release the small ones regarded as ACTH storage.

\section{Materials and Methods}

Male Wistar-Imamichi rats, 45 days of age, were used. As the first experiment, the rats were surgically thyroparathyroidectomized, and then sacrificed 3, 5, $7,15,30,50,90$ and 200 days after the operation respectively. At autopsy, the examination was made macroscopically whether or not the remaining small parts of thyroid tissues hypertrophied compensatorily. When such remaining ones were detected, the relevant animals were omitted. The number of the animals of successful operation was equally 5 in each group. In addition, two thyroidectomized rats in each group were injected with $500 \mu \mathrm{Ci}$ of ${ }^{131} \mathrm{I}$ to destroy completely the remaining thyroid tissues. After operation, the animals were fed ad libitum on $\mathrm{CE}_{2}$-diet obtained from the Central Experimental Animal Laboratory (Japan) and drinking water, and carefully maintained at $25^{\circ} \mathrm{C}$ of room temperature. No tetanic symptom was observed in all the operated animals though the diet was not supplemented with $\mathrm{Ca}$.

The second experimental group was for the replacement therapy with thyroxine. Five thyro-parathyroidectomized rats were singly injected subcutaneously with D. L. thyroxine, $50 \mathrm{mg} / \mathrm{rat}$, on the 15 th postoperative day, and sacrificed in $6 \mathrm{hr}$. Another subgroup consisting of 5 thyro-parathyroidectomized rats was given daily injections with the same dose of thyroxine for 3 days. These animals were sacrificed $6 \mathrm{hr}$ after the final injection.

The last experimental group was for dexamethasone administration. Five thyro-parathyroidectomized rats were subcutaneously injected with dexamethasone $0.2 \mathrm{mg} / 100 \mathrm{~g}$ daily for 14 days from the 15 th postoperative day. They were sacrificed on the 30 th day of operation.

For electron microscopy, pituitary tissues were fixed in $2 \%$ osmic acid in a $\mathrm{pH} 7.4$ phosphate buffer solution (Millonig, 1961) or in a pH 7.4 veronal acetate buffer solution for $2 \mathrm{hr}$. Some tissues were fixed in a $3 \%$ glutaraldehyde phosphate buffer of $\mathrm{pH}$ 7.4 for $2 \mathrm{hr}$ and fixed again in a buffered $2 \%$ osmic acid solution for $2 \mathrm{hr}$. Following fixation, the tissues were dehydrated in an increasing percentage of cold ethanol, treated with prophylenoxyde for $10 \mathrm{~min}$, infiltrated, and embedded with Luft's epon resin 812 . Thin sections were made with the Porter-Blum ultratome, mounted on copper grids, and stained with a saturated aqueous solution of uranyl acetate and then with the lead solution of Reynalds (1963). The sections were examined with a JEM 7A type electron microscope.

\section{Result}

\section{Effect of thyroidectomy upon the acido- phils}

Three days after thyroidectomy most acidophils were slightly affected in their fine structure, representing the identical picture with the normal acidophils (Fig. 1). The population of the large granules, measuring $350 \mathrm{~m} \mu$ in maximal diameter, was roughly estimated to be lowered in most acidophils beyond the normal scope; there was a slight trend of reduction in number of the large granules (Fig. 1). The incidence of the large granules varied, however, considerably with acidophils. Above all, the acidophils (somatotrophs) full of the large granules were scattered yet, in which rough endoplasmic reticula (ER) were arranged in parallel to constitute the layers of concentric canaliculi (Fig. 2). In 5 days, the number of the large granules in the acidophils was markedly reduced (Fig. 3). Some acidophils showed a degenerative sign; changed in shape from ellipsoid to polygonal and the high electron density of the ground matrix as shown in Figure 4. They sometimes elongated irregularly their poor cytoplasm, in which Golgi vacuoles, lamellae and the granules ranging from 120 to $350 \mathrm{~m} \mu$ in diameter were still preserved. Thus, the acidophils gradually collapsed in keeping the granules in them for a long time. As the degradation became more serious, mitochondria swelled and their cristae became indistinct (Fig. 5). Some acidophils may be of the dysfunctioning state due to thyroxine deficiency. However, the healthy acidophils were usually most densely populated.

Seven days after thyroidectomy, the acidophils (somatotrophs) which had spread over the anterior lobe began to diminish in number 


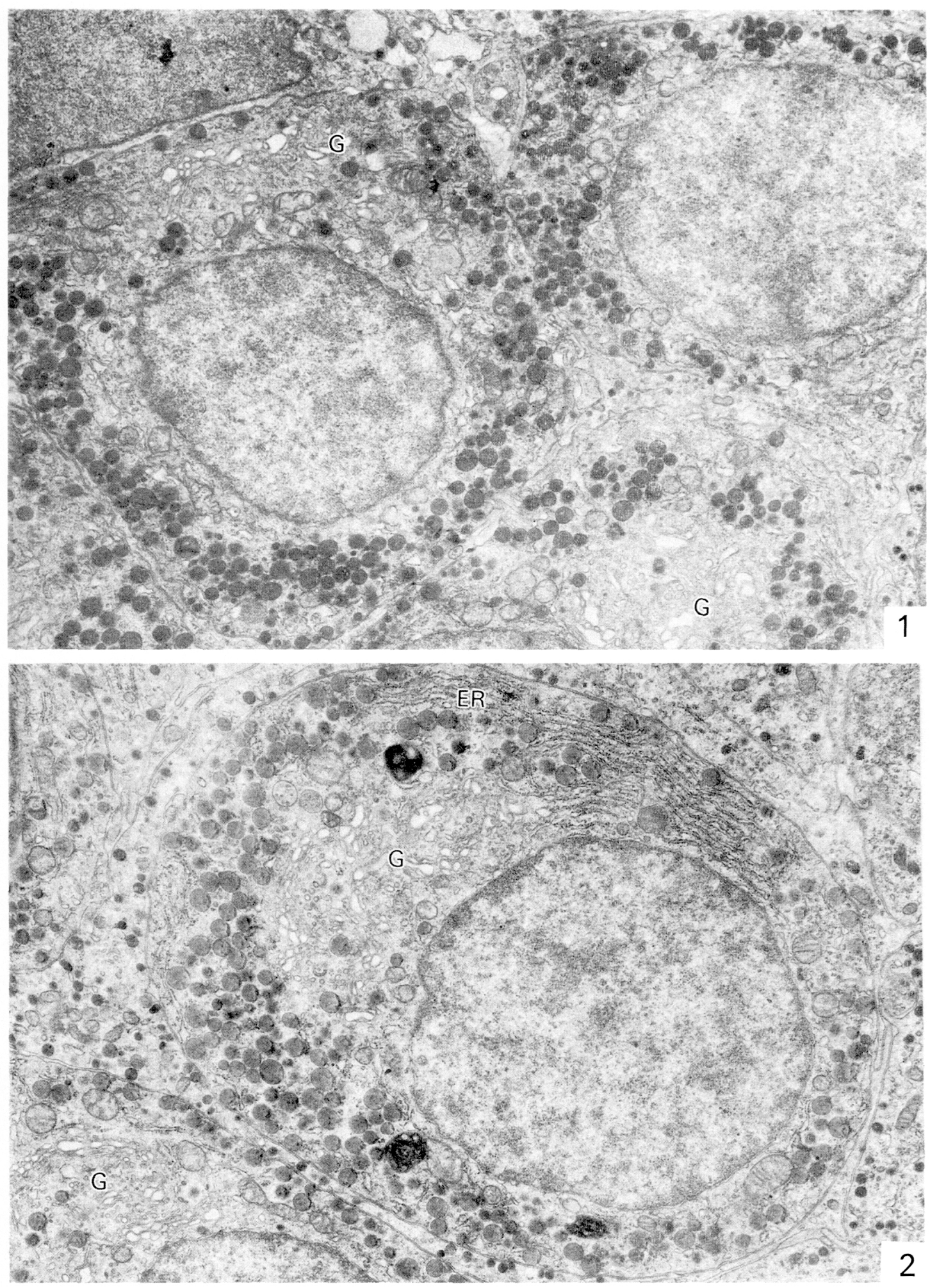

Fig. 1. and 2. Acidophils from the thyroidectomized rats, 3 days after operation. Degranulation of the acidophils is not yet profound, in which large granules $350 \mathrm{~m} \mu$ in diameter are enough accumulated. Golgi apparatus (G) is well developed. The concentric arrangement of endoplasmic reticula (ER) is a characteristic original to the acidophils. Lysosomes are occasionally detectable. $\times 10,000 . \times 11,000$. 


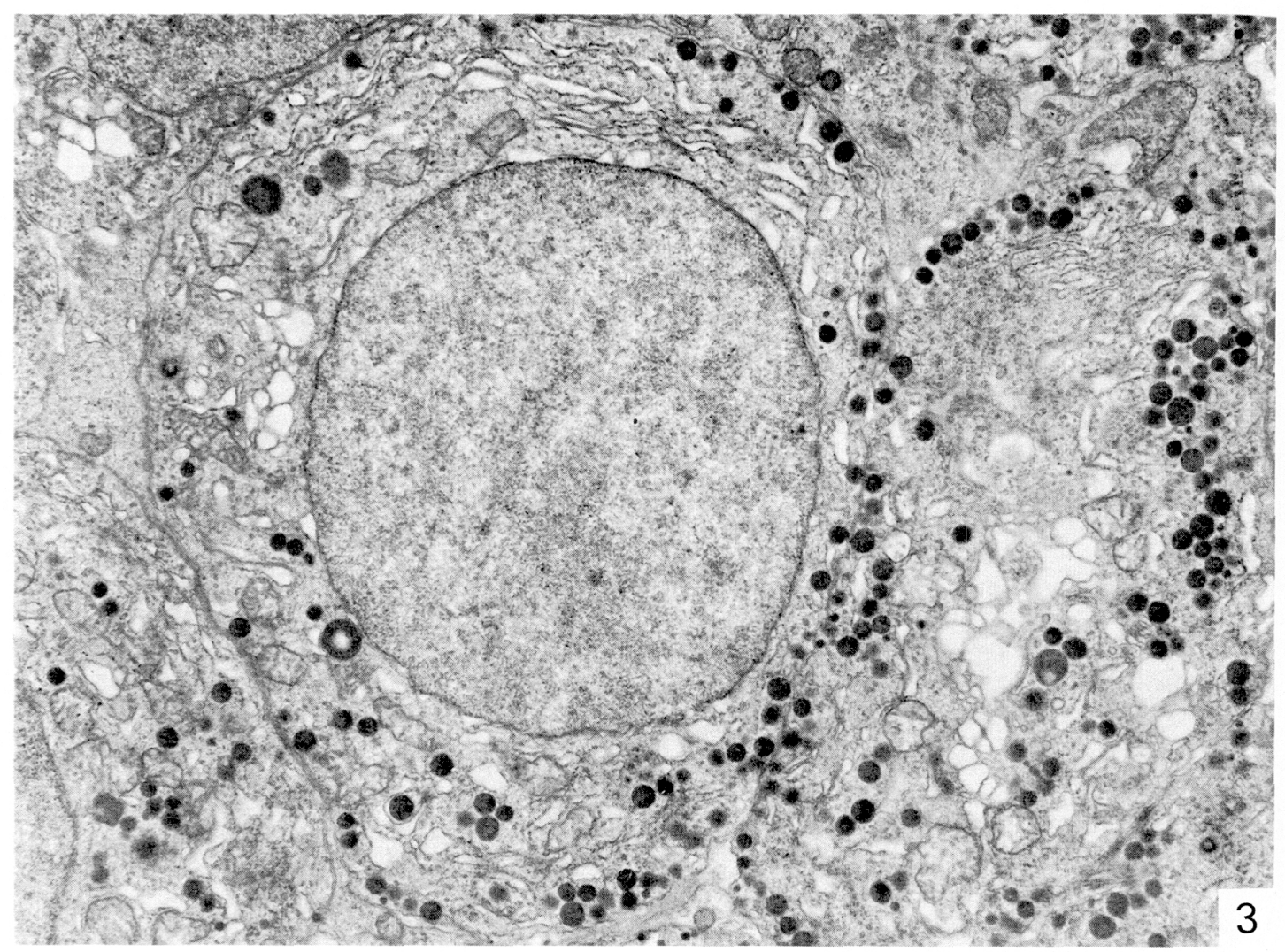

Fig. 3. Five days after thyroidectomy. Although many large granules are released from the acidophils, only a several number of the same granules still remain in the cell-body in which lamellar ER tend to expand. G, Golgi area. $\times 10,500$.

(Fig. 6). Figures 7 and 8 illustrated a kind of acidophil completely devoid of the large granules respectively. Notwithstanding the disappearance of the large granules, some acidophils sufficiently maintained the small granules ranging from 120 to $150 \mathrm{~m} \mu$ in diameter. The picture of eruptocrine secretion of the large granules into the subcapillary space was not detectable. Some acidophils were left in keeping a small number of the large granules at the peripheral portion of their cell-body. The detailed observation showed that a few somatotrophs were still sustained up to the 5 th or 7 th postoperative day. The extent of degranulation varied with acidophils and became more appreciable with the lapse of time after complete removal by radiothyroidectomy.

On the 15th day of operation, most acidophils lost their large granules, bearing a certain similarity to the basophilic cells (Fig. 9). Even under in this condition, the cell distinction was still possible according to the two criteria: 1) the ellipsoid shape and large size of the cell-body, 2) the parallel distribution of rough ER. However, the degranulated acidophils finally revealed the typical polygonal shape and contained dilated or sometimes fragmented ER (Fig. 10). Since they furnished the cytological features analogous with the immature basophils, it was not easy to sharply distinguish them by their cytological features from the latter. The elongated mitochondria may serve 

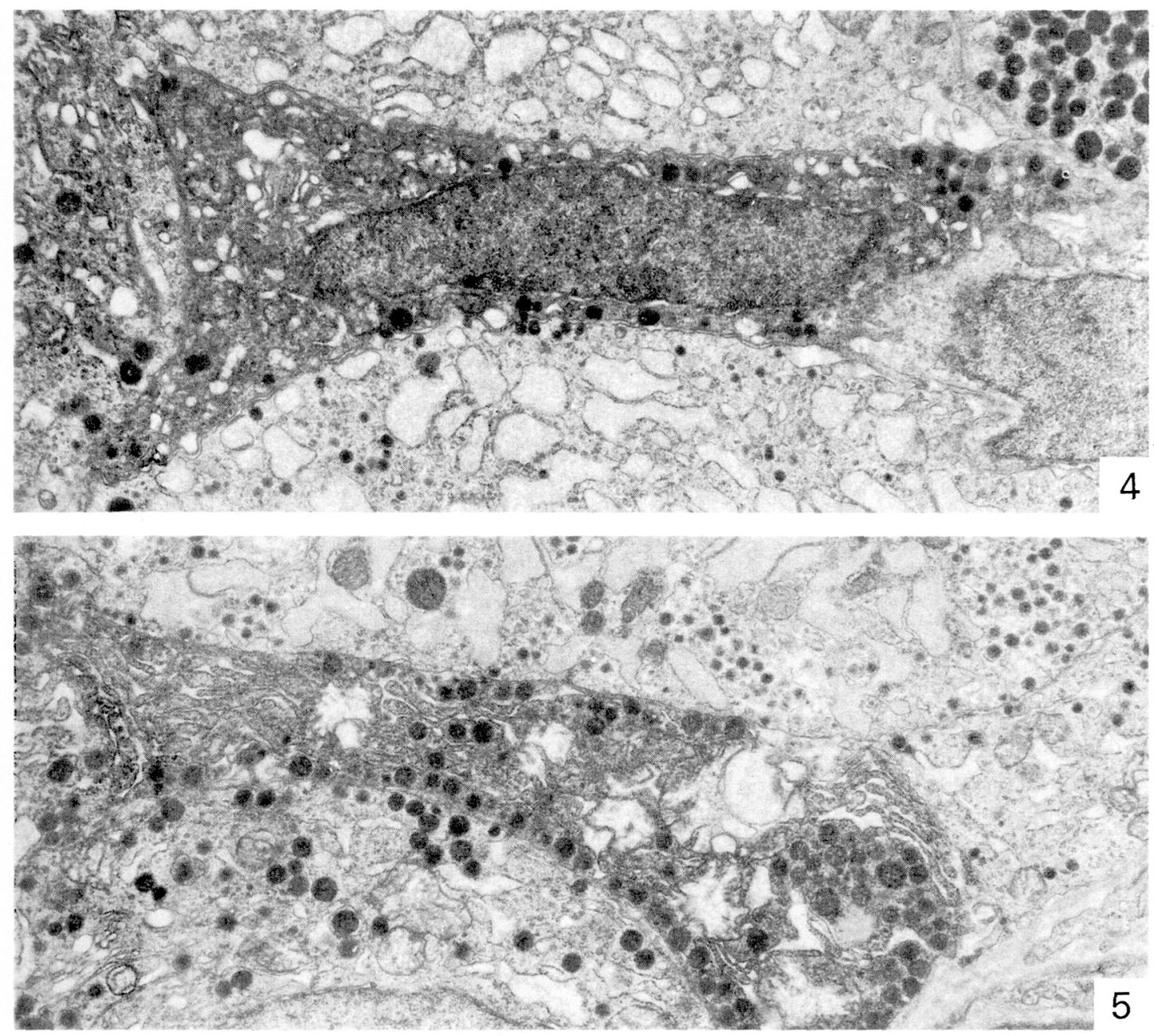

Figs. 4 and 5. Five days after thyroidectomy. Some irregularly shaped acidophils collapse and represent the high electron density of the cell-bodies keeping the large granules. The mitochondria swell and their cristae lare indistinct, because these acidophils undergo the retrogressive change. $\times 9,000 . \times 10,000$.

as only a criterion for their identification.

Thirty, 50, 90 and 200 days after thyroidectomy, the whole anterior pituitary was occupied by the basophilic cells associated with the thyroidectomy cells. All the large granules dispersed from the acidophils. Lysosomes were sometimes accumulated (Fig. 11). Not only the large granules but also the small ones were chronically eliminated from the acidophils (Fig. 11). The agranular acidophils thus developed in the chronical phase of complete thyroidectomy. Their population was lower in the rats with simple surgical thyroidectomy than in those with an additional irradiation.

\section{Effect of replacement with thyroxine} upon the acidophils after thyroidectomy

In the thyroidectomized rats given a single dose of thyroxine, the acidophils recovered rapidly from loss of the large granules. 


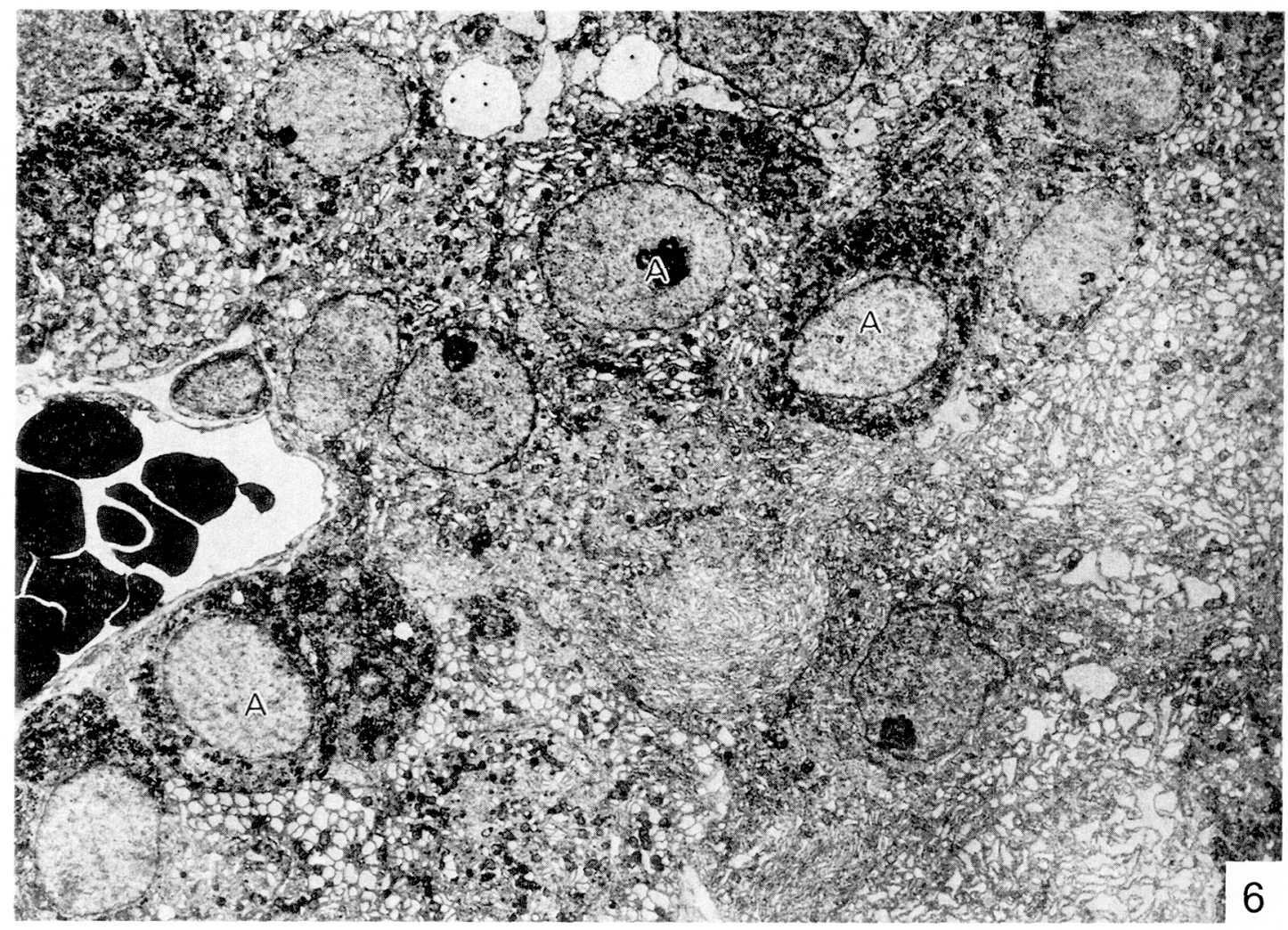

Fig. 6. Anterior pituitary from the thyroidectomized rat, 7 days after operation. The large granules extensively decrease in number in the whole anterior pituitary. Numerous "thyroidectomy cells" characterized by the dense distribution of expanded ER are found. However, the typical acidophils (A, somatotrophs) surely remain. $\times 3,000$.

The large granules were reproduced most effectively even by a single replacement. The degree of regranulation varied considerably from cell to cell, and in this fashion the somatotrophs reappeared (Fig. 12). There was morphological evidence showing that the large granules were made up again in participation with the Golgi apparatus, because the enlarged Golgi sacs and vacuoles occasionally contained the initial granules. Daily injections of thyroxine for 3 days gave rise to the perfect recovery from loss of the large granules in the acidophils (Fig. 13). The reproduced granules ranged 130 to $350 \mathrm{~m} \mu$ in diameter. They seemed to grow in size by thyroxine injections. However, the population of the reverted soma- totrophs was lower in the thyroidectomized thyroxine-treated rats than in the normal. Lysosomal or dense bodies were not changed. The ability of thyroxine to reproduce the large granules was thus unequivocal.

\section{Effects of dexamethasone upon the acidophils after thyroidectomy}

The thyroidectomized dexamethasonetreated rats were distinguished from the control thyroidectomized rats ( 30 days after the operation) by the induced definite change as to the population of small granules in the acidophils. The small granules tended to multiply by dexamethasone (Fig. 14). The voluminous stock of the small granules in some acidophils 




Fig. 7. An acidophil from the thyroidectomized rat, 7 days after operation. One of the cytological features of the affected acidophils is a matter of low granularity. Nevertheless, the small granules about $130 \mathrm{~m} \mu$ in diameter numerously store up without being released. Indentification of the degranulated acidophils is possible according to the feature of elongated large mitochondria and paralled distribution of lamellar ER. $\times 9,500$. 


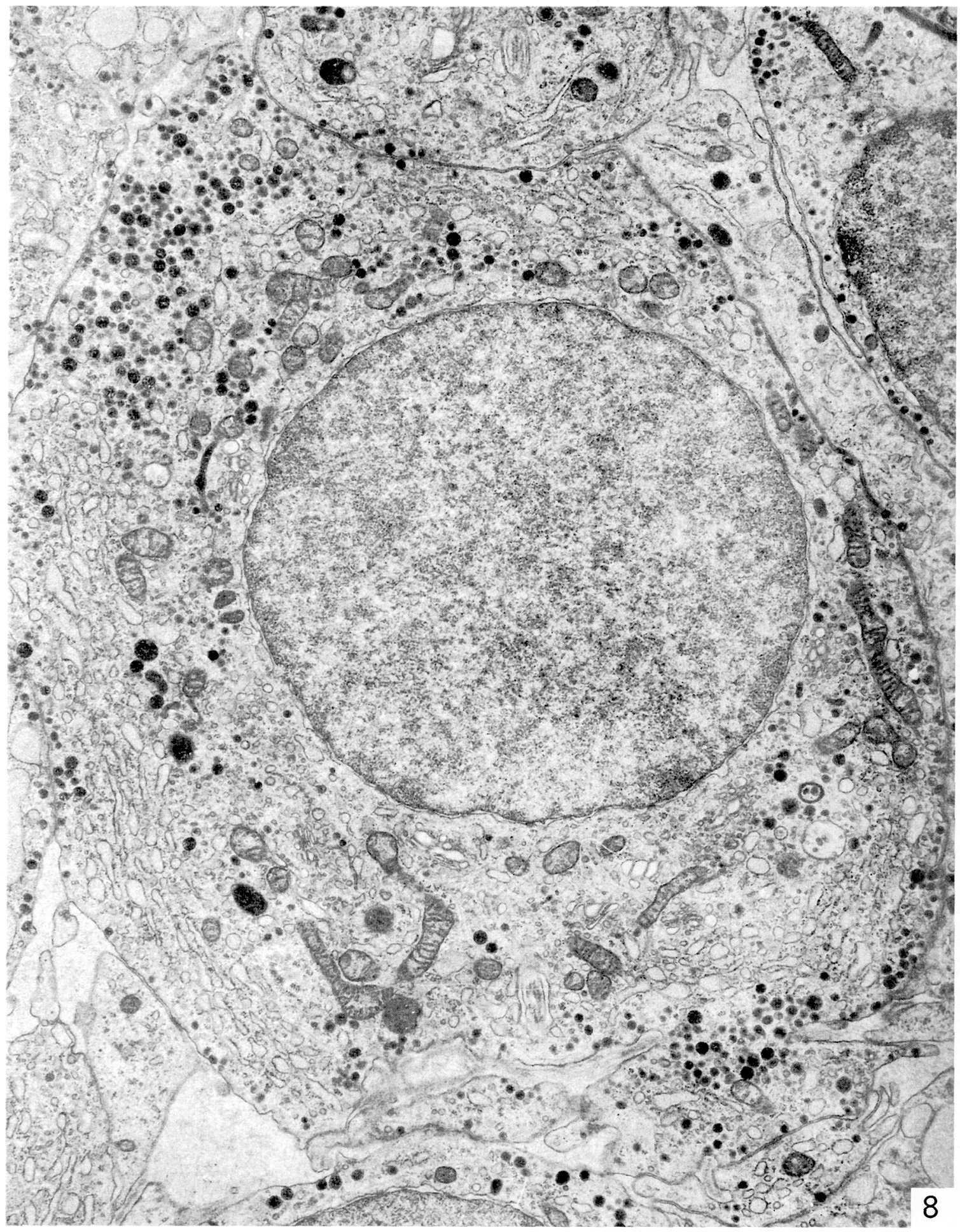

Fig. 8. An acidophil from the same rat. Similarly, this acidophil keeps only the small granules in its cell-body. Acidophils modify their shape into the polygonal cells complicatedly outlined. Note the slight dilation of the canalicular ER that are located at the peripheral area of the cells. $\times 9,200$. 

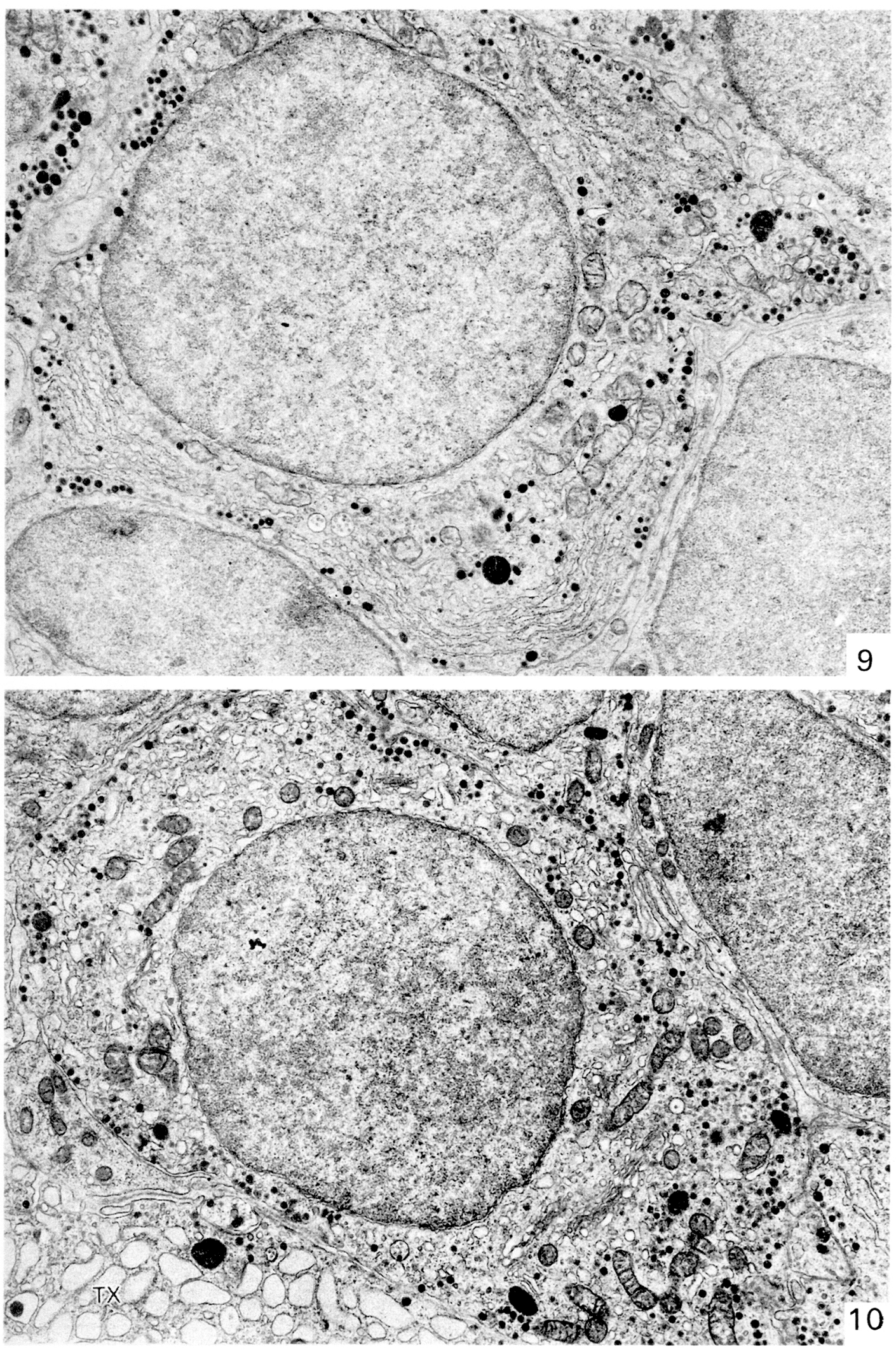

Figs. 9 and 10. Acidophils from the thyroidectomized rats, 15 days after operation. These cells lose completely their large granules. Because of the polygonal shape, it is not easy to distinguish them in their fine structure from the immature basophils. However, the parallel arrangement of the lamellar ER and the elongated mitochondria may serve as the indices for identifying their cell origin. As illustrated in Figure 10, the lamellar ER are dilated to some extent in this acidophil. $\times 9,500$. 

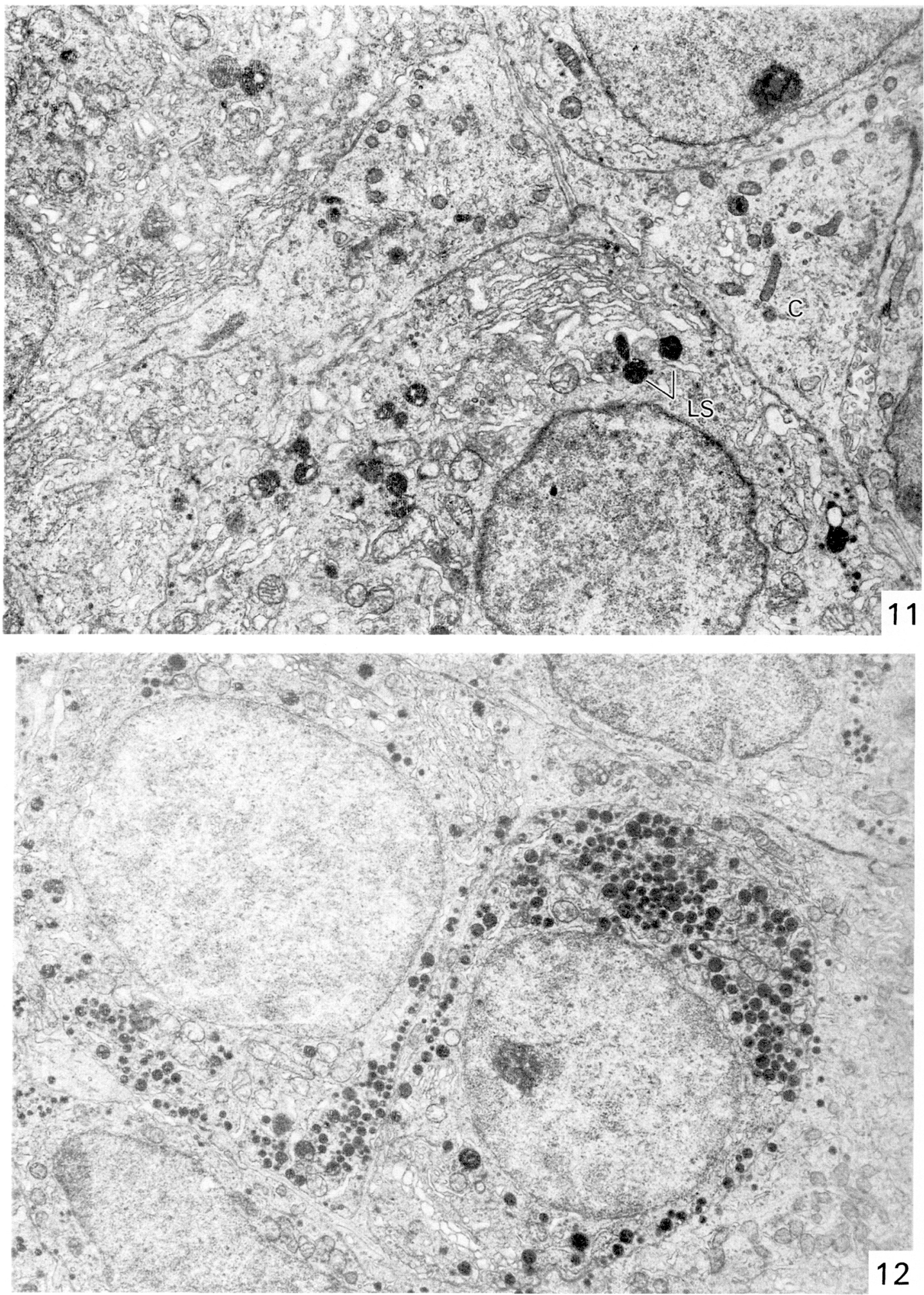
was the main event (Fig. 14). But this compound also gave no remarkable influence to reproduce the large granules. Some young or infantile acidophils accumulating the medium size of granules ranging from 200 to $300 \mathrm{~m} \mu$ in diameter ultimately were scatered again (Fig. 15A'), but they never matured into the typical somatotrophs.

\section{Discussion}

It was already corroborated by our foregoing light microscopical work (Yoshimura and Ishikawa, 1969) that the acidophils decreased remarkably in number following thyroidectomy. It has been shown in this electron microscopy that the acidophils themselves do not completely disappear, but are only deprived of their large granules. The eruptocrine (open) secretion of the large granules has been pointed out to perform in the acidophils by many investigators (Sano, 1962; Maillard, 1963; Salazar and Peterson, 1964; Tixier-Vidal and Picart, 1967). Recently, De Virgillis et al. (1968) and Couch et al. (1969) observed electron microscopically the performance of this mode of secretion by the stimulation of hypothalamic extract and GRF. In our opinion the open secretion is related to an abnormal secretion, i.e., "hunger secretion" in the acidophils, and could be conducted only under some extraordinary stimuli. Because of the infrequent detection of the granule extrusion, there may be a likelihood that the hormonal substances stored in the large granules are diffused into the ground matrix of cytoplasm, and pass freely through the cytomembrane as molecules. The other possibility is that the large granules may be reduced in size by liquefying their peripheral portion and turned into the small ones at emergency of thyroxine deficiency. Pituitary GH content is lowered by thyroidectomy (Contopoulos and Koneff, 1963). According to Ieiri (1971), the synthesis of GH was greatly suppressed by thyroidectomy, whereas its release was stimulated; prolactin synthesis was, however, enhanced by thyroidectomy whereas its release was lowered by it. In our observation the large GH granules decreased in number and the so-called prolactin granules did not increase in number. Potvliege (1968) claimed that the degranulated acidophils following thyroidectomy took an appearance of prolactin cells. Smith and Farquhar (1966) reported that when the secretory activity of the acidophils was generally suppressed the storage granules were fused with lysosomes. The present observations did not present any close relationship between lysosomes and prolactin granules.

Retrogressive acidophils were occasionally found only at the early phase after thyroidectomy. The possible lifespan of the isolated chromophobes transforming into the acidophils was suggested by Ohtsuka et al. (1971) using in vitro system. In reference to their in vitro findings, it is postulated that only the fully matured or old acidophils could be naturally degraded en route following thyroidectomy. In fact, as far as the detectable retrogressive sign of the acidophils was concerned, the present in vivo findings were in agreement with the in vitro findings of Ohtsuka et al.

Fig. 11. Agranular acidophils completely devoid of any granules, 50 days after thyroidectomy. Three agranular acidophils are deprived of the granules of any size except the lysosomal bodies (Ls). Somewhat dilated lamellar ER are distributed at the peripheral area of the cells. C, chromophobe containing the pseudolumen equipped with the microvilli. $\times 10,000$.

Fig. 12. Six hours after a single injection of thyroxine $(50 \mathrm{mg} / \mathrm{day} / \mathrm{rat})$ on the $15 \mathrm{th}$ day of thyroidectomy. Thyroxine has reproduced most efficuously the granules (130 to $300 \mathrm{~m} \mu$ in diameter) in the degranulated acidophils. The central two acidophils enough accumulate the granules growing in size. $\times 9,500$. 

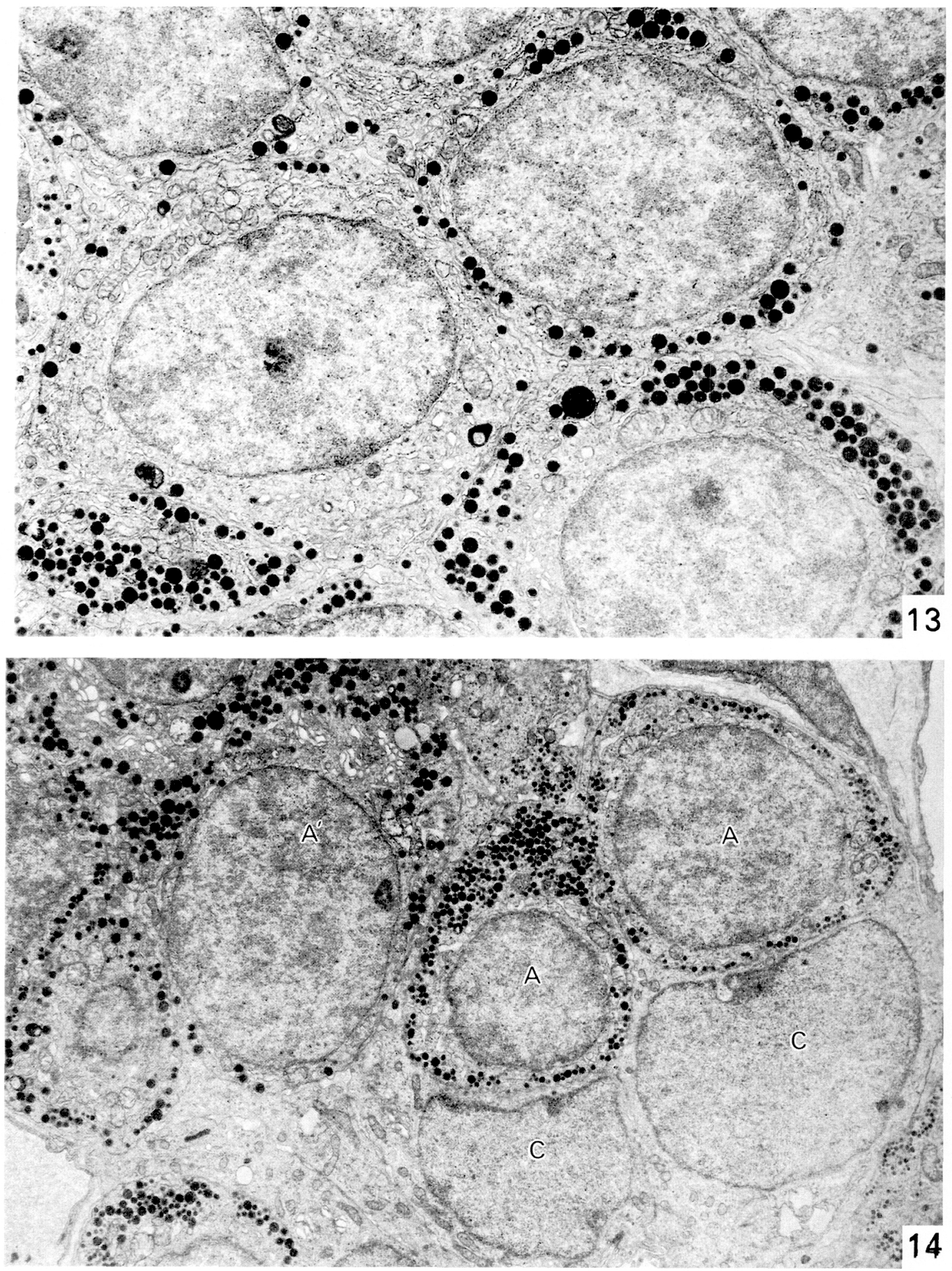


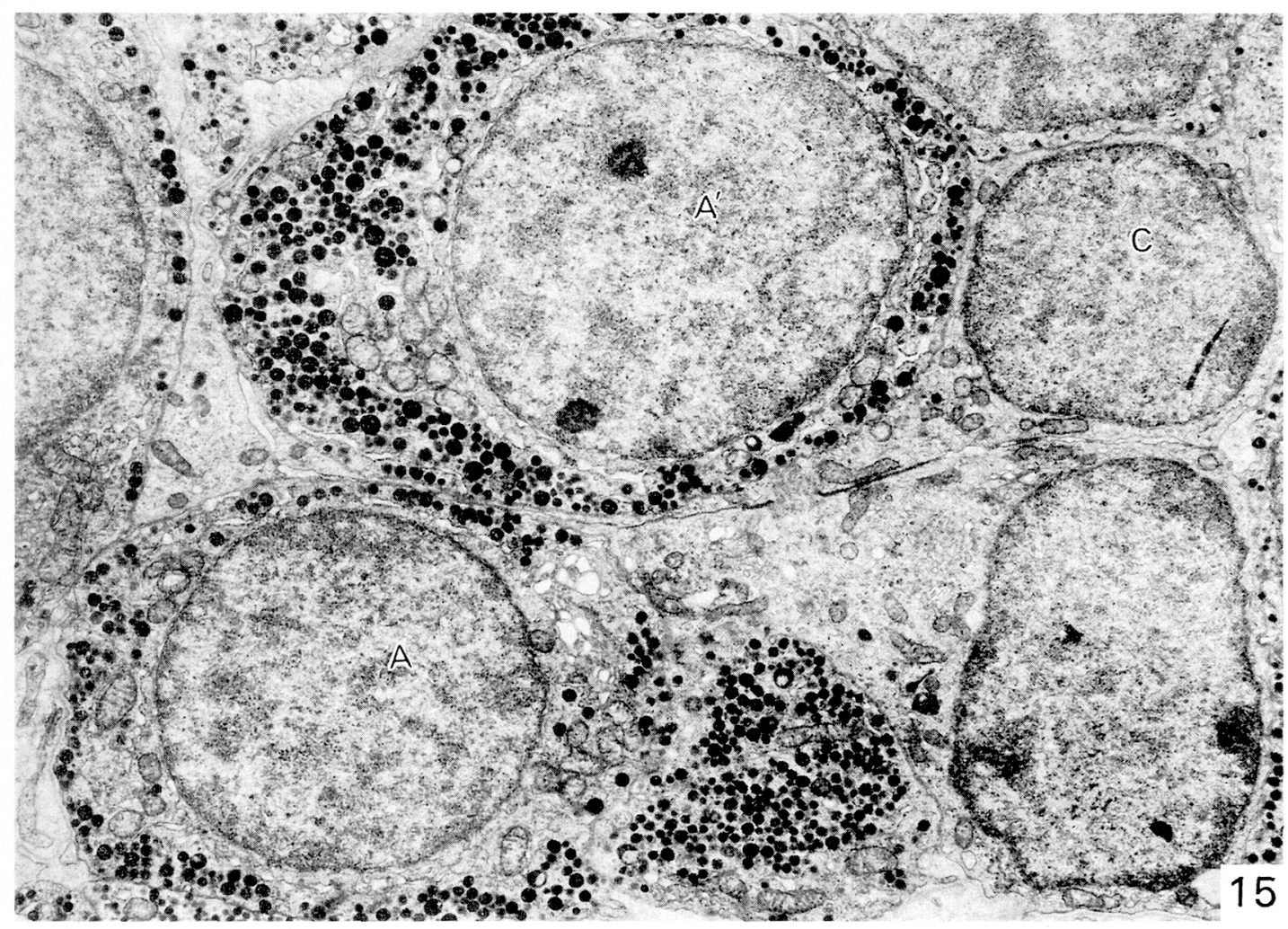

Fig. 15. Under the same condition. The restoration of loss of granules is quite evident. Although the population of the acidophils (A) become obviously higher, the reproduced granules in them are usually smaller in size than those with thyroxine injections, meassuring approximately 130 to $300 \mathrm{~m} \mu$ in their maximal diameter (compare with Fig. 13). $\mathrm{A}^{\prime}$, acidophils such as containing the larger granules. ch, chromophobe. $\times 11,000$.

(1971): Degeneration did not, however, take place in all the healthy acidophils. Many young active acidophils may survive.

In this experiment, such acidophils as holding the numerous small granules instead of large ones were certainly demonstrated to occur following thyroidectomy. This kind of acido- phil was first demonstrated in vitro by Ohtsuka et al. (1971), who cultured the isolated chromophobes in CRF-media, and made them differentiate into the mature acidophils. The present study dealt with the first information of the existence of an acidophil that accumulated only the small granules in vivo.

Fig. 13. Three-day injections of thyroxine $(50 \mathrm{mg} /$ day/rat) from the 15 th day of thyroidectomy. Numerous acidophils store the large granules with the equivalent size of 200-350 $\mathrm{m} \mu$. Most acidophils are fully recovered from loss of their large granules following thyroidectomy $\times 10,000$.

Fig. 14. Daily injections of dexamethasone $(0.2 \mathrm{mg} /$ day $/ 100 \mathrm{~g})$ for 15 day from the 15 th day of thyroidectomy. The small granules whose diameter is about $130 \mathrm{~m} \mu$ increase in number in many acidophils (A), among which the other acidophils $\left(A^{\prime}\right)$ are intervened (left, top). The latter contains a number of larger granules, ranging from 150 to $300 \mathrm{~m} \mu$. c, chromophobe. $\times 9,500$. 
As thyroxine was found in this study to conduct an activity to reproduce the large granules in the degranulated acidophils after thyroidectomy, the loss of the large granules seemed to be really specific to thyroxine deficiency. The small granules were not discharged at the moment of thyroxine deficiency. Some acidophils lost, however, their granules completely during the chronical phase, but all acidophils did not always do so. The agranular acidophils was, however, low in population throughout the experiment. The fate of the degranulated acidophils was not exactly determined.

In our observation, the small granules increased in number by dexamethasone (DM). Sakuma and Knobil(1970)pointed out that DM exerted no influence on $\mathrm{GH}$ release whereas it prevented ACTH release. Sawano et al. (1969) gave a large amount of steroid to the neonatal rats within $24 \mathrm{hr}$ of birth, and found that the pituitary GH content and hypothalamic GRF activity were lowered within 5 weeks of birth. The present study showed that DM had a principal potency to accumulate the small granules in the acidophils, but a slight influence to produce the large GH granules. According to our electron micrographs, the $\mathrm{GH}$ granules within the celles seemed to be higher in frequency in the thyroidectomized dexamethasone-treated rats than in the thyroidectomized control ones. It is most likely tenable that the large granules may be made up by increasing the dimension of the small ones. Many investigators (Pecile et al., 1965; Schalch, 1967; Meyer and Knobil, 1967; Caracia et al., 1968; Schalch and Reichlin, 1968; Brown et al., 1971; Kokka et al., 1972.) paid attention to a close relationship between the secretions of ACTH and GH. If ACTH and $\mathrm{GH}$ are really synthesized in the same acidophils, then the co-existence of $\mathrm{GH}$ and ACTH granules is favourable for the explanation of this relationship.

\section{References}

Amerbury, O. F., A. N. Contopoulos, and A. A. Koneff (1965). Acta endocrinol. 48, 355.

Brown, G. M., D. Schalch and S. Reichlin (1971). Endocrinology 88, 956.

Caracia, J. F., I. I. Geschwind (1968). Growth hormone. Excerpta Med. Found. Milan, 1968, p. 267.

Contopoulos, A. N., M. E. Simpson and A. A. Koneff (1958). Endocrinology 63, 642.

Contopoulos, A. N. and A. A. Koneff (1963). Acta endocrinol. 42, 275.

Couch, E. F., A. Arimura, A. V. Schally, M. Saito and S. Sawano (1969). Endocrin$\operatorname{olog} y$ 85, 1084.

De Virgillis, G., J. Meldolesi, and F. Clementi (1968). Ibid. 83, 1278.

Herlant, M. (1964). Intern. Review of Cytol. 17, 299.

Ieiri, T. (1971). Jap. J. Physiol. 21, 551.

Ishikawa, H., Y. Ohtsuka, F. Soyama and F. Yoshimura (1972). Endocrinol. Japon. 19, 215.

Knigge, K. M. (1955). Anat. Rec. 112, 295.

Knigge, K. M. (1958). Ibid. 130, 543.

Kokka, N., J. F. Carcia, R. Gorge and H. W. Ellott (1972). Endocrinology 90, 735.

Koneff A. A., R. O. Scow, M. E. Simpson, C. H. Li and H. M. Evans (1949). Anat. Rec. 104, 465.

Maillard, M. ;1963). J. Microsc. 2, 85.

Meyer, Y. N. and E. S. Evans (1964). Endocrinology 74, 748.

Meyer, V. and E. Knobil (1967). Ibid. 79, 1016. Millonig, G. (1961). J. Biophys. Biochem. Cytol. 9, 409.

Ohtsuka, Y., H, Ishikawa, T. Omoto, Y. Takasaki and F. Yoshimura (1971). Endocrinol. Japon. 18, 133.

Pecile, A., G. Ferrasio, G. Falconi and E. E. Miller (1965). Proc. Soc. Exp. Biol. Med. 130, 425.

Potvliege, P. R. (1968). Anat. Rec. 160, 595.

Purves, H. D. and W. E. Griesbach (1946). 
J. Endocrinol. 13, 365.

Reynalds, E. S. (1963). J. Cell Biol. 17, 208.

Sakuma, M. and E. Knobil (1970). Endocrinology 86, 890 .

Salazar, H. and R. R. Peterson (1964). Amer. J. Anat. 115, 199.

Sano, M. (1962). J. Cell Biol. 15, 81.

Sawano, S., A. Arimura, A. V. Schally, T. W. Redding and S. Schapiro (1969). Acta endocrinol. 61, 57.

Schalch, D. S. (1967). J. Lab. Clin. Med. 69, 256.

Schalch, D. S. and S. Reichlin (1968). Growth hormone. Excerpta Med. Found. Milan, 1968, p. 211.

Schooley, R. A., S. Friedkin, E. S. Evans (1966). Endocrinology 79, 1053.

Smith, R. E. and M. G. Farquhar (1966). J. Cell Biol. 31, 319.

Solomon, J. and R. O. Greep (1959). Endocrinology 65, 158.

Tixier-Vidal, A. and R. Picart (1967). J. Cell Biol. 35, 501.

Yoshimura F. and H. Ishikawa (1969). Endocrinol. Japon. 16, 69. 